\section{FRACTURE OF THE SPINAL COLUMN WITH AND WITHOUT CORD INJURY}

\section{NORMAN SHARPE, M.D. NEW YORK}

When the subject of fracture of the spinal column is under consideration, we think of it in terms of cord symptoms-impairment of motility and sensation, or paralysis with disturbance of sphincteric control. This is natural, for in by far the greater number of fractures of the spine, the cord or its roots are involved, and the bony fracture itself is a minor hurt compared to the possible result if the cord also is injured.

There are, however, a large number of spinal fractures (Pearce Bailey estimates this to be one third of all cases) in which the cord and its roots escape damage. Unless careful examination is made, these cases are apt to be diagnosed as sprain or contusion. In a recent article $\mathrm{I}^{1}$ reported such a case, a fracture dislocation of the second cervical vertebra without damage to the cord. Since then I have seen five other cases, in some of which the bone injuries were such that it is difficult to understand how the cord escaped involvement.

In four of these cases the fracture occurred in the vertebral bodies, in two of them the bodies being almost completely crushed. Yet these patients were able to stand and move after the accident. As we know that many of the posterior arches or laminae can be removed without materially weakening the spine, and, as we have just seen, crushing of a vertebral body does not render one unable to stand erect,

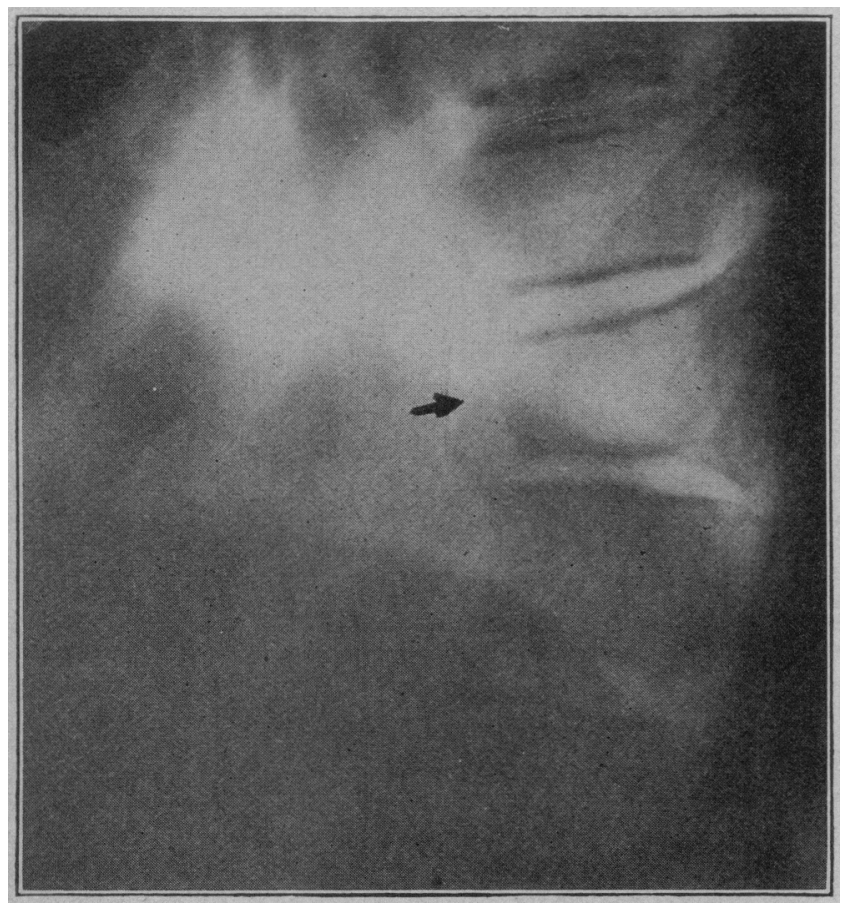
Fig. 1 (Case 1).-Fracture of the body of the eleventh dorsal
vertebra.

it is apparent that the main support or strength of the spinal column lies in the articulations on the transverse processes. And it is rare in fracture by indirect force to have the cord injured (except by hemorrhage)

1. Sharpe, Norman: Am. Jour. Med. Sc., 1916, 152, 865. unless there is rupture of these articulations. The converse is also true, that the most severe injuries of the cord are sten when these articulations are ruptured, the familiar unilateral or bilateral fracturedislocation of one or more vertebrae.

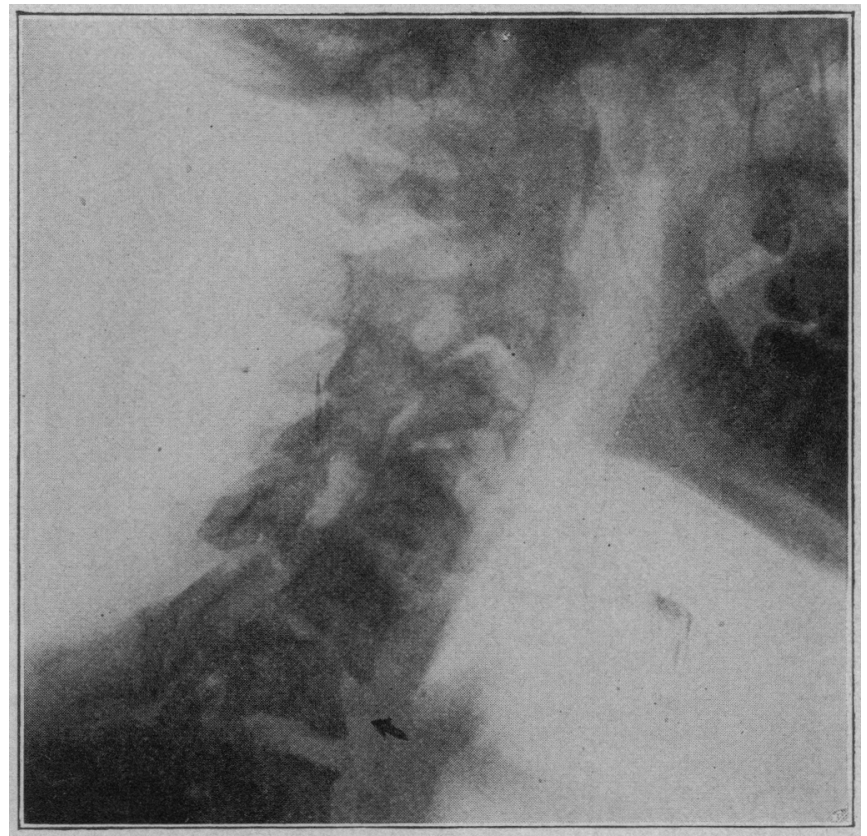

Fig. 2 (Case 2).-Fracture-dislocation of the sixth cervical vertebra.

In fracture-dislocation, the displaced vertebra may remain displaced, or spring back partially or completely into its normal position, leaving as the only signs of its dislocation the signs of cord injury. These signs may vary from partial paralysis to complete abolition of all function below the lesion, giving rise to the suspicion that the cord has been completely crushed at the point of injury. But, as was pointed out in a former article, ${ }^{1}$ complete abolition of function below the lesion in a spinal fracture does not prove that the cord is completely crushed or severed, or even that it is damaged beyond repair. This has been shown time and again at operation, and also in the after-results in unoperated cases.

In a case recently seen by me, one and a half years after the accident, there had been a fracture of the fifth and sixth cervical vertebrae, with complete loss of function below the lesion. On the ground that this showed complete destruction of the cord, operation was withheld. Three months after the accident there was slight return of power in the right leg and partial return of sensation over the body below the lesion. At this time operation was again withheld, on the ground that the improvement was too slight to make it worth while to operate, and, on the other hand, that as the condition was improving it would be better to wait and see how much it would improve. Eighteen months after the accident the patient reported that improvement had ceased at the end of one year. He could weakly raise the arms, but could not bring them down, and could weakly extend and flex the right foot and leg. There was hypesthesia to all forms of sensation below the lesion, with complete loss of sphincteric control. He could not stand or even sit. Laminectomy was done and the laminae and pedicles of the fifth and sixth cervical vertebrae were found fractured and jammed about the cord, severely compressing it. The dura had not been torn, and the cord, though pale, was of normal appearance otherwise. Following operation there has been gradual return of power, so that now, six months after operation, there is fair strength in the arms, especially in the 
right, and the patient is able to walk with crutches. Hypesthesia has been replaced by areas of hyperesthesia and paresthesia. He is still improving.

Though helped by late operation, how much more benefit would this patient have received by an early laminectomy. The only reliable sign that proves a complete crush of the cord, and the only contraindication to early operation, is a bony deformity so great as to show complete obliteration of the spinal canal. By the term "early operation" is meant a laminectomy after the patient has rallied from the initial shock of the injury. Naturally if the injury has been so severe, or if the patient's vitality is such, that he cannot rally from the condition of shock, any operation at this time will hasten death. A safe general rule to follow is not to operate while the pulse is above 110 .

In many fractures of the spinal column without cord signs, the fracture has been entirely overlooked. In the case of a woman previously reported who fell on a stairway striking the back on a step, there were no signs of nerve involvement, and a fracture was not suspected. Months after the accident and when all pain had long since disappeared, cord symptoms appeared and gradually increased. Only when they became marked was attention directed to the old accident, and roentgenoscopy disclosed marked callus formation at the site of the injury, the twelfth dorsal and first lumbar vertebrae.

In the absence of cord symptoms and no marked protrusion or "knuckle" of the spine, the diagnosis is apt to be "simple sprain or contusion." Thus in Case 3 , in which there was a marked crushing of the body of the twelfth dorsal vertebra, at the hospital to which the patient was first taken he was told that the injury was simply a contusion, and no roentgenogram was taken.

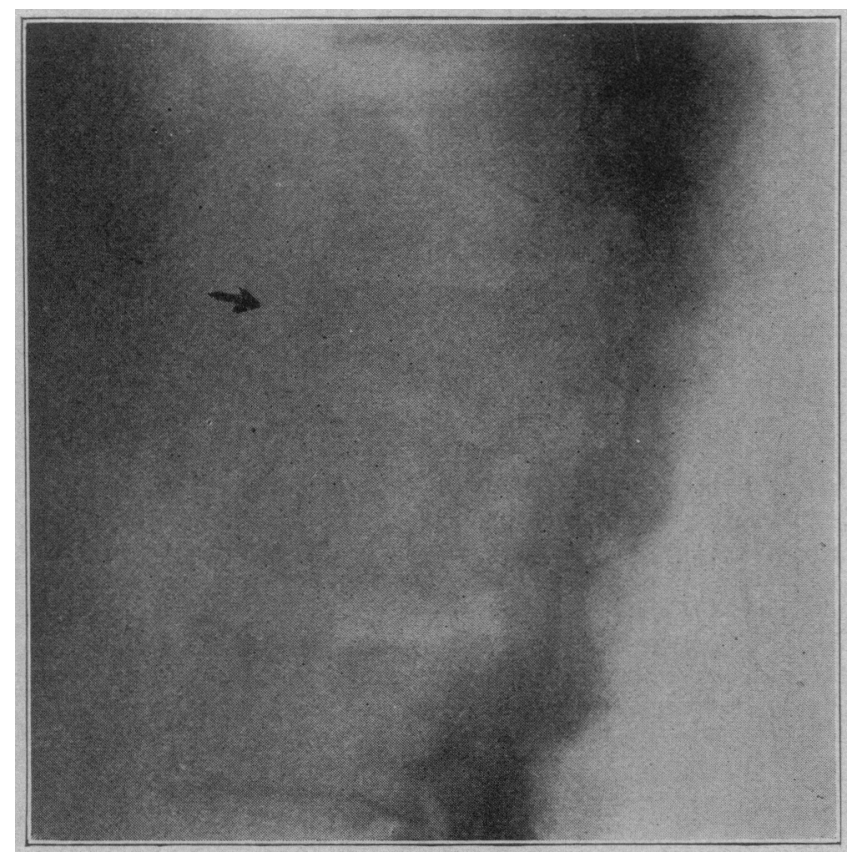

Fig. 3 (Case 3).-Crushing of the first lumbar vertebral body.

If other injuries are present, the spinal fracture without cord involvement is apt to be overlooked. In Case 4 , in which severe burns of the arms and shoulders were sustained in addition to the injury of the back, the burns were treated as the principal lesion, and in the absence of cord symptoms no attention was given to the spine, though the patient complained of pain in the lumbar region. Three weeks later, when the burns were nearly healed, the persistence of the pains directed attention to the spine, and examination revealed alteration in the normal spinal curve in the

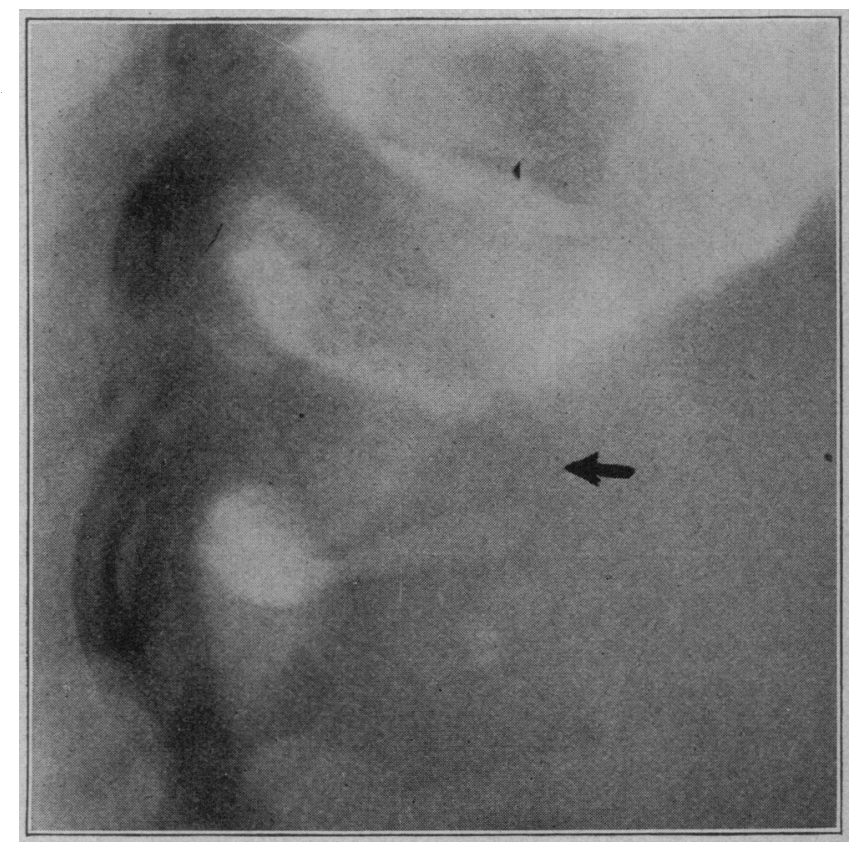

Fig. 4 (Case 4.--Crushing of the twelfth dorsal vertebral body.

dorsal lumbar region. Roentgenoscopy disclosed a marked crushing of the body of the twelfth dorsal vertebra.

These cases indicate the necessity of careful examination, both clinical and by the roentgen ray, of all cases of suspected injury to the spine. Although in neither of these cases did the failure to recognize a spinal fracture result seriously, it is readily conceivable that in a patient able to move about in bed with the fracture not immobilized, sudden twisting or turning movements by the patient or his attendants might easily convert a fracture without cord signs into a fracture with marked and serious cord involvement. Also failure to recognize a fracture and no attempt made to restore the normal spinal curve may result in weakening of the spinal column and more or less permanent disability, with perhaps appearance later of cord symptoms, due to new bone formation. This is especially true when the fracture occurs in the vertebral bodies.

The treatment of fractures of the spinal column without cord symptoms is immobilization. In fractures of the cervical vertebrae, immobilization is best secured by a plaster collar. If the fracture is high in the cervical region, an extension should be made from the collar about the forehead. If the fracture lies in the lower cervical region, an extension should also include the upper chunk. After from six to ten weeks, when all pain and tenderness have disappeared, the plaster may be followed by a stiff leather collar, which gives support but is more comfortable and allows greater freedom of movement. If the fracture lies in the laminae of the dorsal or lumbar vertebrae, a molded splint of plaster on each side of the spinal column and connected by transverse bands above and below the lesion will be found a satisfactory way of immobilizing the fracture and preserving the normal 
outline of the spinous processes. Fracture of the vertebral body is best treated by overextension on a Bradford frame, which is much more comfortable and efficacious than a plaster jacket.

\section{REPORT OF CASES}

The following cases, some of which were seen with Dr. William Sharpe, are examples of extensive fractures of the spine following severe injuries, without cord signs:

CASE 1.-A. M., man, aged 22, while employed as a bell boy in September, 1915, fell through the dome of a skylight, a distance of 18 feet, striking the floor on his head and shoulders. Unconscious and severely contused, he was taken to a hospital where a diagnosis was made of fractured skull; this was changed a few days later to cerebral contusion. The patient was unconscious for three days, and stuporous and dazed for two weeks. There were no signs of cord involvement present at any time. No operation was done, and he was discharged from the hospital "improved," but complainng of headache and pain in his back. When seen, two months later, his cere-

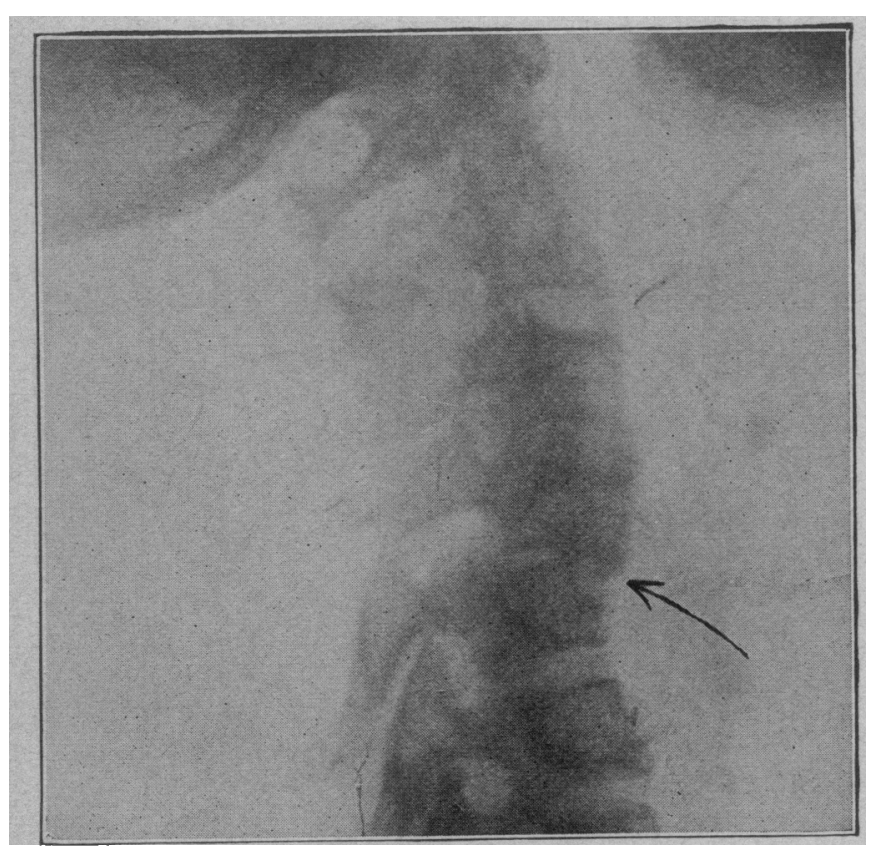

Fig. 5 (Case 5).-Fracture-dislocation of the fifth cervical vertebra.

bral condition had almost entirely cleared up except for occasional dull headache. His chief complaint was pain and weakness in the back aggravated by standing or walking. This pain was severe enough to prevent his returning to work. Examination disclosed a projection backward of the spinous process of the eleventh dorsal vertebra and alteration of the normal spinal curve in this region. Roentgenoscopy revealed moderate crushing of the body of the eleventh dorsal vertebra and slight dislocation backward of this vertebra; the upper borders of the twelfth dorsal vertebral body were "lipped," and there was evidence of slight crushing of this vertebra also. The neurologic examination was negative. The tendon and skin reflexes were present and normal; there was no Babinski reflex, no ankle clonus, no sensory changes and no disturbance of the sphincters. A metal brace was applied, causing slight overextension of the spine at this point. When seen two years later, the patient was found to be normal except for some spinal rigidity at the dorsal lumbar junction and slight alteration of the normal spinal curve. From habit he was still wearing the brace, which he was advised to discard.

CASE 2.-R. H., a man, aged 20 , while playing polo in October, 1915, was thrown from his horse, striking on his neck and shoulders. He was not unconscious, but complained of severe pain in the neck radiating to the back of the head. He was able to walk off the field. He remained in bed two days with severe pain in the neck. There was no radiation of pain in the arms and legs and no sphincteric disturbance. Two weeks later the lower tendon reflexes were found to be somewhat increased; there was no Babinski reflex; the abdominal reflexes were present and equal; there was no impairment of motility or of sensation in either the upper or the lower extremities. Roentgenoscopy (by Dr. Caldwell) revealed a fracture-dislocation of the sixth cervical vertebra with backward displacement of one-half inch. Naturally, in view of the fact that there were no signs of cord injury found, no operation was done, but the head and neck were placed in a plaster collar. The patient made an excellent recovery, so much so that in the following year he rowed on a 'varsity crew. There have been no complaints up to the present time.

CASE 3.-S. B., a man, aged 30, in April, 1917, fell 40 feet from a window, first striking his back on a wooden railing 10 feet below the window, and then continuing to fall 30 feet, landing on a wooden floor on his left side. When he struck the railing he had severe pain, and says he "thought his back was broken." $\mathrm{He}$ was not unconscious and had no pain nor numbness in the legs. When lifted he was able to stand alone; he was taken to a hospital, where he was told that the injury to the back was a contusion. No roentgenogram was made. He had severe pain in the lumbar region and the left flank. There was no sphincter trouble, and he passed no blood. He was out of bed on the eleventh day, and left the hospital in two weeks. He was at home a week, in and out of bed, with severe pain in the back and some pain on the inner side of the left thigh. During this week he tried various "stunts to loosen up his back," getting down on the floor on his hands and knees and twisting about, kicking out with the feet, etc. This caused pain. Three weeks after the accident, examination revealed an alteration in the normal spinal curve at the dorsolumbar junction, a kyphosis, and protrusion of the spinous process of the first lumbar vertebra. Roentgenoscopy revealed marked crushing of the body of the first lumbar vertebra. There were no motor or sensory changes, and the reflexes were unaltered. There was some tenderness to pressure over the spine and marked tenderness in the left flank. The tenderness on the inner side of the left thigh disappeared the following week. The patient was placed on a Bradford frame with overextension of the spinal column for four weeks. When he left the hospital he was fitted with a steel brace, which he wore during the day for eight months. Examination nine months after the injury showed the spine strong and supple, with slight projection of the spinous process of the first lumbar vertebra. There were no root pains and no signs of motor or sensory involvement of the cord or roots.

CAse 4.-C. P., a woman, aged 18, was trapped by fire on the fifth floor, in March, 1917. After clinging to the windowsill and being burned extensively on the arms and back, she fell and struck the middle of the back across an iron bar at the first story, and then fell to the ground. She was dazed but not unconscious, and after being lifted up could stand erect and move about. She was brought to the hospital in an ambulance. She complained of pain in the back at this time more than of the burns. There was no pain nor any numbness in the legs. The burns were treated and no attention was paid to the back. Thirty hours after the injury the temperature rose to $105 \mathrm{~F}$. and fell shortly to 102 ; on the seventh day it was normal and continued so. The patient moved about in bed, but there was no weakness in the legs, though these movements caused pain. Three weeks later, because of the persistence of the pain, examination of the back was made and a protrusion found in the dorsolumbar region. Roentgenoscopy revealed marked crushing of the twelfth dorsal vertebra. Careful neurologic examination at this time showed no impairment of motility or sensation. The patient was placed on a Bradford frame in hyperextension, and the pain ceased in a day or two. After five weeks the patient was fitted with a rigid brace for the spine, which she wore for several months. Examination one year later showed her to be normal and able to work, and with no complaint.

CASE 5.-H. B., a man, aged 47 years, while working as a ship rigger, in March, 1918, fell 35 feet and was unconscious 
for fifteen minutes. The right side of the head and face was badly cut and three ribs were broken, but his chief complaint was pain in the back of the neck. He was unable to turn his head in any direction on account of the pain in the neck. $\mathrm{He}$ was taken to a hospital, where he was told that his neck was sprained. He was twelve days in bed, being treated for the fractured ribs and other injuries, though his chief complaint was pain in the neck. No roentgenogram was taken at this time. Three weeks later, twenty-two days after the injury, the pain persisting, a roentgenogram was taken, which showed a dislocation backward of the fifth cervical vertebra with fracture of the body of the fourth cervical. Neurologic examination at this time was entirely negative. There was no impairment of motility or sensation and no alteration of the deep or superficial reflexes. The patient carried his head in a peculiar stiff manner, though he could move it without much discomfort. A plaster collar was applied and he is still under observation.

315 West Ninety-Seventh Street.

\section{CANCER OF THE ORAL CAVITY, JAWS AND THROAT}

TREATMENT BY ELECTROTHERMIC M̈ETHODS OR IN COMBINATION WITH SURGERY, THE ROENTGEN RAY AND RADIUM, WITH AN ANALYSIS OF TWO HUNDRED CASES SO TREATED *

\section{WILLIAM L. CLARK, M.D.} PHILADELPHIA

Electrothermic methods are peculiarly adapted to the treatment of cancer within the mouth. Malignant tissue (including bone) occurring in any part of the oral cavity, comprising the lips, buccal surface, tongue, floor of the mouth, alveolus, hard palate, antrum, tonsils, pharynx, epiglottis, larynx and proximal end of the esophagus, may be destroyed with one electrothermic operation.

It is not necessary to split the cheek surgically to render a growth accessible to treatment, since the exposure secured by the use of a mouth gag, cheek retractors, traction on tongue by means of a suture or tongue forceps, or by the use of an endoscope is

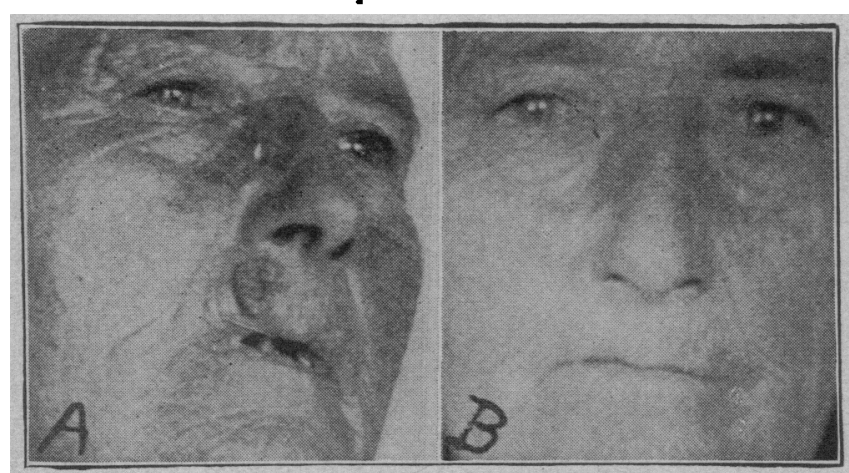

Fig. 1.- $A$, basal cell epithelioma of the upper lip in a woman, aged 72 , referred by Dr. William Hamilton of Philadelphia. One desiccation treatment was given in September, 1914. $B$, result. Note absence of contracted scar. No recurrence in nearly four years.

sufficient to permit the destruction of a growth. A tongue may be coagulated to the base and then excised without hemorrhage.

In addition to the desiccation or coagulation of tissues and the sealing of blood and lymph channels, the heat penetrates beyond the area totally destroyed

* Read before the Section on Stomatology at the Sixty-Ninth Annual Session of the American Medical Association, Chicago, June, 1918. and devitalizes malignant cells without impairing the healthy tissue, thus lessening the likelihood of local recurrence or metastasis and conserving the maximal amount of normal tissue.

Blood vessels encountered in the oral cavity are blocked by the current, and secondary hemorrhage rarely occurs. The efficiency of electrothermic methods is increased in some cases by the judicious use of operative surgery, the roentgen ray and radium.

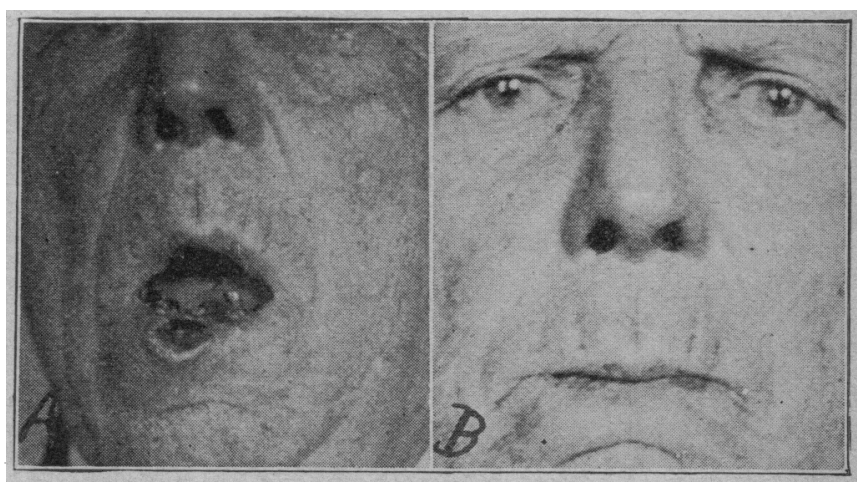

Fig. 2.- $A$, epithelioma of lower lip, a recurrence after surgical excision, in a man, aged 75 , referred by Dr. Paul Cassidy of Philadelphia. One desiccation treatment under local anesthesia was given in April, 1915. $B$, result of treatment. Note absence of contracted scar and regeneration of lost tissue in lip. No recurrence in more than three years.

\section{ELECTROTHERMIC METHODS}

The methods to be considered are electrodesiccation and electrocoagulation. The desiccation method is one by means of which malignant growths of small or moderate size may be destroyed by the utilization of heat of just sufficient intensity to desiccate or dehydrate the tissues, and is produced by a monopolar high frequency current of the Oudin type, which is applied to the lesion by means of a steel needle or other pointed metallic applicator (usually steel knitting needles) which may be cut and curved, if necessary, to suit the case under treatment. The desiccation method is of advantage when the lesion is localized and a good cosmetic result is to be desired, and is subject to such control as to area and depth that a very small growth even on the cornea may be successfully treated without injury to vision, as may a growth on the vocal cords be destroyed without impairing phonation. The very slight trauma and absence of secondary inflammation probably explains the absence of scarring and the success obtained in treating delicate structures.

Electrocoagulation is produced by a bipolar high frequency current of the d'Arsonval type, is more penetrating. and intense in action than the desiccation method, and is utilized to destroy large growths, including those that involve bone.

There are many variations of technic in the application of both methods to suit the requirements of the individual case, which need not be considered in detail here. ${ }^{1}$ The heat from high frequericy currents, unlike that from the thermocautery and galvanocautery, is not transmitted by contact, but is generated within the tissues by the resistance offered to the current. The

1. Pfahler, G. E.: Electrothermic Coagulation and Roentgenotherapy in the Treatment of Malignant Disease, Surg., Gynec. and Obst., December, 1914. Clark, W. L.: Electrical Desiccation as an Adjunct to Surgery, with Special Reference to the Treatment of Cancer ibid, Aurt August, 1912; The Desiccation Treatment of Congenital and New Growths of the Skin and Mucous Membranes, The Journal A. M. A. ; Electrothermic Methods in the Treatment of Rodent Ulcer, Urol, and Cutan. Rev., November, 1917. 